\title{
Emergency Response of Indian Hajj Medical Mission to Heat Illness Among Indian Pilgrims in Tent-Clinics at Mina and Arafat During Hajj, 2016
}

\author{
Inam Danish Khan ${ }^{1 *}$, Syed Bahavuddin Hussaini ${ }^{2}$, Shazia Khan ${ }^{3}$, Faiz MH Ahmad ${ }^{1}$, Faisal Ahmad Faisal ${ }^{4}$, Muhammad \\ Arif Salim ${ }^{5}$, Razzakur Rehman ${ }^{6}$, Syed Asif Hashmi ${ }^{1}$, Bushra Asima ${ }^{7}$, Muhammad Shaikhoo Mustafa ${ }^{8}$
}

${ }^{1}$ Army College of Medical Sciences and Base Hospital, New Delhi, India

${ }^{2}$ Madurai Medical College, Government Rajaji Hospital, Madurai, India

${ }^{3}$ Specialist Obstetrics and Gynaecology, INHS Kalyani, Vishakhapatnam, India

${ }^{4}$ Specialist Paediatrics, MH Roorkee, India

${ }^{5}$ Hospital Administrator, Assam, India

${ }^{6}$ Specialist Physiology, Guwahati, India

${ }^{7}$ Army Hospital Research and Referral, New Delhi, India

${ }^{8}$ Public Health Consultant, Chennai, India

Corresponding Author: Inam Danish Khan, MD, Assistant Professor of Microbiology, Army College of Medical Sciences and Base Hospital, New Delhi 110010, India. Tel: +91-9836569777, Fax: +91-11-25693490, Email: titan_afmc@yahoo.com

Received October 2, 2017; Accepted November 18, 2017; Online Published December 2, 2017

\begin{abstract}
Introduction: Extreme heat claims more lives than all other weather-related exposures combined. Hajj rituals at Mina, Arafat, and Muzdalifah involve a minimally-clothed, moving assemblage of 3.5 million pilgrims who are exposed to a harsh, hot, desert climate during physically challenging outdoor rituals and unsheltered night stays, rendering them prone to heat illness, dehydration, and sunburn. This cross-sectional study assessed the emergency response of the Indian Hajj Medical Mission to overwhelming heat illnesses in Mina and Arafat among Indian pilgrims during Hajj, 2016.

Methods: In 2016, 88 patients affected by the heat were brought to central tent-clinics at 36 maktabs in Mina and Arafat that were established by the Indian Hajj Medical Mission. Patients were offered rapid external evaporative cooling (wet towels) and cold intravenous saline infusion on patient couches and wheelchairs.

Results: The incidence of heat illness among Indian pilgrims in 2016 was 0.62/1000. The ratio of males to females was 1.8:1. Mean ages of males and females were $62.2 \pm 7.43$ and $52.6 \pm 9.3$, respectively. Pre-existing conditions, such as diabetes mellitus and hypertension, were present in $93.2 \%$ of the patients. The most common presentations included hyperthermia, fatigue, and restlessness. Heatstroke presented in five patients and resulted in one fatality. Twenty-eight patients were referred to Saudi hospitals, and 12 of them were institutionalized. Exertion related to the stoning of Satan ritual during late morning and afternoon hours was the leading cause of heat illness.

Conclusion: The overwhelming incidence of heat illness among Indian pilgrims in the critical five-day period of the Hajj represents the tip of the iceberg as the Hajj attracts over 3.5 million pilgrims from 200 countries annually. Heat illness is difficult to manage in the presence of pre-existing comorbidities and mandates clientele education and outreach warning systems to enhance resilience capital amongst Hajj pilgrims, sportspersons, outdoor enthusiasts, and military personnel.

Keywords: Hajj, Heat IIIness, Heat Exhaustion, Heat Stroke, Mass Gathering Medicine
\end{abstract}

Citation: Khan ID, Hussaini SB, Khan S, et al. Emergency response of Indian Hajj Medical Mission to heat illness among Indian pilgrims in TentClinics at Mina and Arafat during Hajj, 2016. Int J Travel Med Glob Health. 2017;5(4):135-139. doi:10.15171/ijtmgh.2017.26.

\section{Introduction}

Heatstroke has been a major cause of concern worldwide throughout the second half of the 20th century owing to rapid urbanization, industrialization, and consequent climate change. In the United States, extreme heat claims more lives than all other weather-related exposures combined (hurricanes, tornadoes, floods, and earthquakes). ${ }^{1}$ Heatwaves in 2003 and 2015 claimed 70000 lives in Europe and the Indian subcontinent, respectively. The 2001 and 2007 Intergovernmental Panel on Climate Change (IPPC) warned about increased heat-related premature mortality among vulnerable populations. ${ }^{2}$

Copyright $\odot 2017$ The Author(s). This is an open-access article distributed under the terms of the Creative Commons Attribution License (http:// creativecommons.org/licenses/by/4.0), which permits unrestricted use, distribution, and reproduction in any medium, provided the original work is properly cited. 
The Hajj is an annual peaceful mass gathering of over 3.5 million pilgrims congregating in densities of nine people/ $\mathrm{m}^{2}$ from 200 countries at Mecca, Saudi Arabia. The Hajj involves effort-intensive prayers, supplications, and rituals for spiritual edification. Mina, located five $\mathrm{km}$ away from the main city of Mecca, upholds the simultaneous congregation of 3.5 million Hajj pilgrims for five days at a stretch. Hajj pilgrims are accommodated in several thousand allotted and labeled fire-resistant tents spread over an area of $18 \mathrm{~km}^{2}$ in the Saudi Arabian desert, which witnesses harsh climatic conditions. Arafat, located a further $22 \mathrm{~km}$ from Mina, is the scene of what is considered the most important ritual of the Hajj pilgrimage. The crowd from Mina attends Arafat on a required day, followed by a night of sleeping under the open sky at Muzdalifah. ${ }^{3-5}$

Mass-gathering medicine at the Hajj is challenged by issues of healthcare accessibility, emergency response systems, on-site treatment, referral, and evacuation in addition to challenges of human support such as shelter, food and water, transportation, sanitation, and overcrowding. The Hajj has historically experienced high morbidity and mortality due to heat illnesses. The critical five days in Mina, Arafat, and Muzdalifah involve a minimally-clothed moving assemblage exposed to a harsh, hot, desert climate during physically challenging outdoor rituals and an unsheltered night stay in Muzdalifah, which renders them prone to heat illness, dehydration, and sunburn..$^{4-6}$

This cross-sectional study assessed the emergency response of the Indian Hajj Medical Mission to overwhelming incidence, presentation, management, and follow up of heatrelated illnesses such as heat hyperpyrexia/syncope, heat exhaustion, and heat stroke among Indian pilgrims during Hajj, 2016.

\section{Methods}

A total of 88 patients affected by the heat who presented at 36 tent-clinics at different maktabs in Mina and Arafat during the critical days of the Hajj, 2016 from the 8th to the 12th of September, 2016 were included in this prospective crosssectional study after approval and consent were obtained. Patients reporting/brought to the maktab tent-clinics were referred/brought to central tent-clinics, one each in Mina and Arafat, established to cater to the moving assemblage during the Hajj. All patients presenting with effects of heat at any time of day or night were included in the study under inclusive sampling. Similar presentations under conditions attributable to pre-existing comorbidities were excluded.

The emergency response plan comprised rapid cooling followed by an assessment of related risk factors such as diabetes mellitus, hypertension, cardiovascular morbidity, respiratory disease, mental health disorders, and a contributory history of medication. Clinico-demographic parameters, headache, fatigue, thirst, dizziness, vomiting, cramps (abdomen/ extremities), edema, breathlessness, confusion, restlessness, agitation, irritability, delirium, perspiration, flushed dry skin, vitals, syncope, unconsciousness, coma, hematuria, and loss of bowel and bladder control were assessed. Heat exhaustion and heat stroke were deduced from pale perspiring skin
}

and flushed dry skin, respectively, along with suggestive features. Due to limitations of time, patient couches and patient monitoring infrastructure were set up in low resource, makeshift tent-clinics. Patients were managed on patient couches, plastic chairs, and wheelchairs during treatment and observation until disposal, referral, or evacuation due to the absence of beds in the maktab clinics and the Arafat clinic and fewer beds in the central tent-clinic in Mina. Heat exposure variables such as duration of sun/outdoor exposure and physical exertion were assessed.

Random blood glucose testing could only be done for 42 patients at the central tent-clinic in Mina. Rectal temperatures and postural drops in blood pressure could not be evaluated due to the high patient throughput. Rapid cooling was achieved with external evaporative cooling (wet towels) and cold intravenous saline infusion. Clinico-demographic parameters, pre-existing health conditions, clinical presentation, treatment, referral, and mortality were analyzed using descriptive statistics with SPSS version 21 .

\section{Results}

The 88 (57 males and 31 females) patients of Indian/South Asian descent reporting with effects of heat included walkin or brought-in cases and patients reported by other clinics. Patients who were found restless, lost, or unconscious along the route or in their tents were brought by relatives, friends, or tent-mates or by philanthropic volunteers identifying them as Indians through wrist bands. Foreigners without wrist bands who appeared to be Indian were also brought. One patient was received by the Moassasa clinic.

The total number and incidence rate of heat illness among Indian pilgrims were $140000,0.62$ per 1000 for Hajj, 2016. The male-to-female ratio was 1.8:1. The most common age brackets for males and females were 51-70 years and 4160 years, respectively. Mean age was $62.2 \pm 7.43$ (95\% CI: 47.3-77.2) for males and $52.6 \pm 9.3$ (95\% CI: 41.6-63.5) for females. Pre-existing conditions, i.e. diabetes mellitus and hypertension, were present in 93.2\% (95\% CI: 85.9-96.8) of cases, and $67.1 \%$ of patients were on medications; albeit, compliance was poor (Table 1).

The most frequent etiology for heat illness was physical exertion, related to the stoning of Satan ritual during late morning and afternoon hours. The round-trip distance for the stoning ritual from the pilgrim's residential tent and back was approximately $6 \mathrm{~km}$, and only part of the route was shaded. Most pilgrims deteriorated on the way back to their tents as they walked on roads exposed to the sun. Most patients were exposed to the heat for 2-4 hours. The most common signs of heat illness were hyperthermia, fatigue, and restlessness (Table 2). Twenty-four patients had hypoglycemia at presentation. Five patients presented with heatstroke which resulted in one fatality at the Mina hospital. Twenty-eight patients were referred from tent-clinics to Saudi hospitals in Mina and Arafat; 12 of these patients were kept under institutionalized care.

\section{Discussion}

Mass gatherings evoke a high incidence of environment 
Table 1. Age, Gender, Comorbidity Profile, and Lead Diagnosis of Patients With Heat Illnesses During Hajj, 2016

\begin{tabular}{|c|c|c|c|c|}
\hline Age (y) & Males & Females & Cumulative percentage & $95 \% \mathrm{Cl}$ \\
\hline $31-40$ & 1 & 3 & 4.5 & $1.7-11.1$ \\
\hline $41-50$ & 3 & 11 & 15.9 & $9.7-24.9$ \\
\hline $51-60$ & 16 & 14 & 34.1 & $25-44.5$ \\
\hline $61-70$ & 31 & 4 & 39.8 & $30.2-50.2$ \\
\hline$>70$ & 4 & 1 & 5.6 & 2.4-12.6 \\
\hline \multicolumn{5}{|c|}{ Pre-existing Comorbidity } \\
\hline Diabetes mellitus (DM) & 18 & 13 & 35.2 & $26.1-45.6$ \\
\hline Hypertension & 13 & 9 & 25 & $17.1-34.9$ \\
\hline Other cardiovascular disease & 1 & 3 & 4.5 & 1.7-11.1 \\
\hline Respiratory disease & 1 & 1 & 2.3 & $0.6-7.9$ \\
\hline DM + Hypertension & 24 & 5 & 32.9 & $24-43.3$ \\
\hline Mental health disorder & 2 & 0 & 2.3 & $0.6-7.9$ \\
\hline Individuals on medications & 37 & 22 & 67.1 & $56.7-75.9$ \\
\hline \multicolumn{5}{|c|}{ Heat Illness } \\
\hline Heat Exhaustion & 24 & 11 & 39.8 & $30.2-50.2$ \\
\hline Heat Stroke & 5 & 0 & 5.7 & $2.4-12.6$ \\
\hline
\end{tabular}

Table 2. Etiology and Clinical Features of Heat Illness and Pre-Existing Health Conditions

\begin{tabular}{|c|c|c|c|}
\hline & No. of Patients & Percent & $95 \% \mathrm{Cl}$ \\
\hline \multicolumn{4}{|c|}{ Etiology } \\
\hline $\begin{array}{l}\text { History of outdoor exposure in } \\
\text { shade }\end{array}$ & 12 & 13.6 & $7.9-22.3$ \\
\hline History of sun exposure & 76 & 86.4 & $77.7-92$ \\
\hline $\begin{array}{l}\text { History of physical exertion while } \\
\text { exposed }\end{array}$ & 79 & 89.8 & $81.7-94.5$ \\
\hline Duration of exposure 1-2 hours & 10 & 11.4 & $6.3-19.7$ \\
\hline Duration of exposure 2-3 hours & 41 & 46.6 & $36.5-56.9$ \\
\hline Duration of exposure 3-4 hours & 37 & 42.1 & $32.3-52.5$ \\
\hline \multicolumn{4}{|c|}{ Symptoms } \\
\hline Headache & 12 & 13.6 & $7.9-22.3$ \\
\hline Weakness/Fatigue/Lethargy & 45 & 51.1 & $40.9-61.3$ \\
\hline Thirst & 15 & 17.1 & $10.6-26.2$ \\
\hline Dizziness & 32 & 36.4 & $28.1-46.8$ \\
\hline Nausea & 34 & 38.6 & $29.2-49.1$ \\
\hline Vomiting & 2 & 2.3 & $0.6-7.9$ \\
\hline Cramps (Abdomen/extremities) & 15 & 17.1 & $10.6-26.2$ \\
\hline Edema & 2 & 2.3 & $0.6-7.9$ \\
\hline Breathlessness & 16 & 18.2 & $11.5-27.5$ \\
\hline \multicolumn{4}{|c|}{ Signs } \\
\hline Confusion & 12 & 13.6 & $7.9-22.3$ \\
\hline Restlessness/Agitation/Irritability & 34 & 38.6 & $29.2-49.1$ \\
\hline Delirium & 18 & 20.5 & $13.3-30$ \\
\hline Pale perspiring skin (Exhaustion) & 47 & 53.4 & $43.1-63.5$ \\
\hline Flushed dry skin (Stroke) & 11 & 12.5 & $7.1-21.1$ \\
\hline Rash & Nil & - & - \\
\hline Hot to touch & 59 & 67.1 & $56.7-75.9$ \\
\hline Strong bounding pulse & 21 & 23.9 & $16.2-33.7$ \\
\hline Rapid weak pulse & 32 & 36.4 & $28.1-46.8$ \\
\hline Tachypnoea & 34 & 38.6 & $29.2-49.1$ \\
\hline Hypertension & 59 & 67.1 & $56.7-75.9$ \\
\hline Hypotension & 15 & 17.1 & $10.6-26.2$ \\
\hline Syncope/Unconsciousness/Coma & 4 & 4.5 & $1.7-11.1$ \\
\hline Hematuria & 2 & 2.3 & $0.6-7.9$ \\
\hline Loss of bowel and bladder control & 4 & 4.5 & $1.7-11.1$ \\
\hline Death & 2 & 2.3 & $0.6-7.9$ \\
\hline Hypoglycemia & $24 / 42$ & 57.1 & $42.2-70.9$ \\
\hline
\end{tabular}

specific medical challenges such as zoonotic diseases, vectorborne diseases, heat illnesses, accidents, and outbreaks requiring emergency medical and public health response systems. ${ }^{7-9}$ The Hajj is regarded as the best mass gathering preparedness effort worldwide; nevertheless, the history of the Hajj is replete with heat illnesses. Major contributors to overall heat stress are mean temperatures reaching $45^{\circ} \mathrm{C}$, humidity approaching $80 \%$, and stagnant atmospheric conditions potentiated by heat dissipation from asphalt and concrete surfaces, vehicle exhaust, Hajj crowds, and human activities. The absence of trees and open spaces contributes further to the urban heat island effect. The heat index climbs to $90^{\circ} \mathrm{C}$ or more..$^{5,10-12}$ Special heat exposure has been reported to have a ten-fold mortality rate compared to annual heatrelated mortality which is primarily attributable to multiorgan damage and cardiovascular compromise. A core body temperature above $41^{\circ} \mathrm{C}$ may be lethal; however, recovery has been reported even at $46^{\circ} \mathrm{C} . .^{511,13}$

Despite the availability of climate control technologies, heat illnesses continue to cause morbidity and mortality in the backdrop of old age; pre-existing cardiorespiratory, renal, endocrine and neuro-psychiatric health conditions; the use of diuretics, sedatives, stimulants, or antihypertensives; and compromised nutrition, hydration, and living standards, especially during the critical five days of the Hajj. Diabetic and hypertensive patients are at higher risk due to peripheral neuropathy, autonomic dysfunction, nephropathy, and antihypertensive medication. The complications of heatstroke include hematuria, psychosis, pulmonary edema, lactic acidosis, renal failure, consumptive coagulopathy, and metabolic abnormalities. ${ }^{14-18}$ Extreme heat, overcrowding, physical exertion, dehydration, language barriers, tough living conditions, and presence in a foreign country for a long duration precipitate stress-related problems. ${ }^{4-6,19,20}$ Extreme heat affects performance and productivity and predisposes people to societal conflicts, violent crimes, and civil wars.,21-24 The emerging incidence of heat illnesses in the backdrop of pre-existing morbidities and complications thereof needs 
active surveillance and threat assessment with pre-determined mathematical models comparable to those of cold injury and altitude illnesses. ${ }^{25-28}$

This study was conducted in limited resource tent-clinics, which prevented the detailed assessment of heat illness, complications, differential diagnoses, and documentation due to the overwhelming throughput of patients. Patients were lost to follow-up during the Hajj pilgrimage due to high mobility. The emergency response to heat illness comprises rapid cooling with ice water immersion/cold shower, iced gastric/ peritoneal lavage, and monitoring of rectal temperature; however, these approaches were not available in tent-clinics. At best, tent-clinics could offer limited investigations and external evaporative cooling. The overwhelming number of patients compromised standards of care and clientele satisfaction, and it led to physical, mental, and compassion fatigue among healthcare personnel. First response along with on-site management form the most important determinants in prognosis. ${ }^{29-32}$ This concept has been elaborated as the "golden hour in heatstroke." 23

A comprehensive, public health surveillance system enabled Hajj organizers to recognize heatstroke as a significant cause of morbidity, which was noticeably reduced after the provision of gratis potable cold water, sun cover, water sprinklers, and air misters along the pilgrimage routes. ${ }^{33-35}$ Nevertheless, opportunities exist for intervention in the preparedness, clientele, and technology fronts. The provision of better heating-ventilation-air conditioning (HVAC) in tents, shaded/sun-proofed roads/causeways and heat relief shelters, more water sprinklers in Arafat and Mina, rapid cooling technology in tent-clinics, and ample ambulance services is mandated. ${ }^{4-6,12}$ Clientele education is required for both selfhelp and first response. Self-help heat preparedness efforts involving choosing to perform the Hajj at a younger age; environmental assessments of temperature, humidity, and dry winds; risk assessment for physical exertion; availability of water, shade, and medical aid; and self-preparedness with light-weight heat/sun protective clothing, increased fluid intake, and intermittent avoidance of heat/sun/exertion are required. Education on religious concessions to Hajj rituals so as to minimize heat exposure and enhance health protection, hydration, and behavioral modification can be disseminated in mosques. ${ }^{36,37}$ Information on first response training on moving patients to shade, administering cold baths/ sponging, providing cold non-alcoholic fluids, elevating feet, and evacuating patients to a medical facility needs to be disseminated to pilgrims in mass gatherings. Pilgrims, caretakers, administrators, and healthcare personnel should be kept in sync with health protection against heat illness through Heat Alert Response Systems based on Wet Bulb Globe Temperature-based assessment so as to prevent social attenuation in lean periods. ${ }^{12,36}$ Technological advancements such as healthcare robots and drones can facilitate rapid relief, the provision of medical supplies, and can minimize human resource deployment in future Hajj pilgrimages. ${ }^{38}$

The IPPC warns about the increasing frequency and/or intensity of heat waves leading to heat-related premature mortality of the urban poor and primarily the elderly in cities

\section{Research Highlights}

\section{What Is Already Known?}

The critical 5 days of the Hajj in Mina, Arafat, and Muzdalifah involve a minimally-clothed moving assemblage exposed to the harsh, hot desert climate during physically challenging outdoor rituals and unsheltered night stays in Muzdalifah, rendering the pilgrims prone to heat illness, dehydration, and sunburn.

\section{What This Study Adds?}

The overwhelming incidence of heat illness among Indian pilgrims in the critical five-day period during the Hajj represents the tip of the iceberg, as the Hajj attracts over 3.5 million pilgrims from 200 countries annually.

Heat illness is difficult to manage in the presence of comorbidities; thus, clientele education and outreach warning-systems are mandated to enhance resilience capital amongst Hajj pilgrims, sportspersons, outdoor enthusiasts, and military personnel

of temperate regions where the largest increases in thermal stresses occur. ${ }^{1,2}$ Thermal balance is regulated through biological heat gain through metabolism, thermogenesis, and muscular activity along with physical heat exchange through evaporation, radiation, conduction, and convention. Heat acclimatization occurs over 7-10 days, enabling a reduction in the sweat threshold, increased sweating, and the increased capacity of sweat glands to reabsorb sweat sodium, thereby enhancing heat dissipation. An enhanced focus on heat acclimatization may help develop community resilience in the long term.

\section{Conclusion}

The overwhelming incidence of heat illness among Indian pilgrims in the critical 5-day period of the Hajj represents the tip of the iceberg, as the Hajj attracts over 3.5 million pilgrims from 200 countries annually. Heat illness is difficult to manage in the presence of comorbidities. Heat illness mandates a greater emphasis on Hajj health preparedness in times of ongoing climate change. A previously targeted endeavor through clientele education and outreach warning systems will enhance resilience capital among people at risk, such as pilgrims, sportspersons, outdoor enthusiasts, and military personnel.

\section{Authors' Contributions}

All authors contributed equally to the study.

\section{Conflict of Interest Disclosures}

None.

\section{Ethical Approval}

Ethical approval was covered by the institutional committee.

\section{Funding/Support}

None. 


\section{Acknowledgements}

The authors would like to thank Dr Majid Ali Khan, Chief Coordinator, Indian Medical Mission for Hajj 2016 and Dr MS Ahmed, Coordinator Azizia, Indian Medical Mission for Hajj 2016, for kind cooperation.

\section{References}

1. Centres or Disease Control and Prevention. Climate effects on Health. http://www.cdc.gov/climateandhealth/effects/default.htm. Accessed March 30, 2017. Published April 18, 2016.

2. Intergovernmental Panel on Climate Change (IPCC) Climate Change 2007: Working Group II: Impacts, Adaption and Vulnerability. Cambridge, UK: Cambridge University Press; 2007. http://www. ipcc.ch/publications_and_data/ar4/wg2/en/contents.html. Accessed February 10, 2017

3. Manoochehry S, Rasouli HR. Recurrent Human Tragedy During Hajj. Int J Travel Med Glob Health. 2017;5(1):36-37. doi:10.15171/ ijtmgh.2017.07.

4. Khan ID, Khan SA, Asima B, Hussaini SB, Zakiuddin M, Faisal FA. Morbidity and mortality amongst Indian Hajj pilgrims: a 3-year experience of Indian Hajj Medical Mission in MassGathering Medicine. J Infect Public Health. 2017. doi:10.1016/j. jiph.2017.06.004

5. Khan ID, Khan S, Khan MA, et al. Indian Medical Mission at Hajj2016: Mass-Gathering Medicine Perspectives, Challenges, and Opportunities in a Mission Posture. Int J Travel Med Glob Health. 2017;5(3):94-101. doi:10.15171/ijtmgh.2017.20.

6. Memish ZA, Stephens GM, Steffen R, Ahmed QA. Emergence of medicine for mass gatherings: lessons from the Hajj. Lancet Infect Dis. 2012;12(1):56-65. doi:10.1016/s1473-3099(11)70337-1.

7. Khan ID, Sahni AK, Sen S, Gupta RM, Basu A. Outbreak of Prototheca wickerhamii algaemia and sepsis in a tertiary care chemotherapy oncology unit. Med J Armed Forces India. 2017. doi:10.1016/j. mjafi.2017.07.012

8. Khan ID, Sahni AK. Rapid Diagnosis of Dengue Outbreaks in Resource Limited Facilities. West Indian Med J. 2017;66(1):4-9. doi:10.7727/wimj.2016.095.

9. Shujaa A, Alhamid S. Health response to Hajj mass gathering from emergency perspective, narrative review. Turk J Emerg Med. 2015;15(4):172-176. doi:10.1016/j.tjem.2015.02.001.

10. Alberini A, Gans W, Alhassan M. Individual and public-program adaptation: coping with heat waves in five cities in Canada. Int J Environ Res Public Health. 2011;8(12):4679-4701. doi:10.3390/ ijerph8124679.

11. Al-Ghamdi SM, Akbar HO, Qari YA, Fathaldin OA, Al-Rashed RS. Pattern of admission to hospitals during muslim pilgrimage (Hajj). Saudi Med J. 2003;24(10):1073-1076.

12. Noweir MH, Bafail AO, Jomoah IM. Study of heat exposure during Hajj (pilgrimage). Environ Monit Assess. 2008;147(1-3):279-295. doi:10.1007/s10661-007-0120-6.

13. Excessive Heat Events Guidebook. Washington, DC: US Environmental Protection Agency; 2006.

14. al-Mashhadani SA, Gader AG, al Harthi SS, Kangav D, Shaheen FA, Bogus F. The coagulopathy of heat stroke: alterations in coagulation and fibrinolysis in heat stroke patients during the pilgrimage (Haj) to Makkah. Blood Coagul Fibrinolysis. 1994;5(5):731-736. doi:10.1097/00001721-199410000-00009.

15. al-Harthi SS, Karrar O, al-Mashhadani SA, Saddique AA. Metabolite and hormonal profiles in heat stroke patients at Mecca pilgrimage. J Intern Med. 1990;228(4):343-346. doi:10.1111/j.1365-2796.1990. tb00243.x.

16. Donoghue AM, Sinclair MJ, Bates GP. Heat exhaustion in a deep underground metalliferous mine. Occup Environ Med. 2000;57(3):165-174. doi:10.1136/oem.57.3.165.

17. Yaqub BA, Al-Harthi SS, Al-Orainey IO, Laajam MA, Obeid MT. Heat stroke at the Mekkah pilgrimage: clinical characteristics and course of 30 patients. Q J Med. 1986;59(229):523-530.

18. Kashmeery A. Physiological studies on heat exhaustion victims among Mecca pilgrims. Acta Med Austriaca. 1995;22(1-2):16-22.
19. Khan ID. Extreme altitude pulmonary oedema (EAPO) in acclimatized soldiers. Med J Armed Forces India. 2012;68(4):339345. doi:10.1016/j.mjafi.2012.04.018.

20. Khan ID. Comorbid Cerebral and Pulmonary Edema at 7010 M/23000 Ft: An Extreme Altitude Perspective J Med. 2013;14(2):153155. doi:10.3329/jom.v14i2.19668.

21. Simister J, Cooper C. Thermal stress in the U.S.A.: effects on violence and on employee behaviour. Stress Health. 2005;21(1):315. doi:10.1002/smi.1029.

22. Trang PM, Rocklov J, Giang KB, Kullgren G, Nilsson M. Heatwaves and Hospital Admissions for Mental Disorders in Northern Vietnam. PLoS One. 2016;11(5):e0155609. doi:10.1371/journal. pone.0155609.

23. Horowitz BZ. The golden hour in heat stroke: use of iced peritoneal lavage. Am J Emerg Med. 1989;7(6):616-619. doi:10.1016/07356757(89)90285-4.

24. Seraj MA, Channa AB, al Harthi SS, Khan FM, Zafrullah A Samarkandi $\mathrm{AH}$. Are heat stroke patients fluid depleted? Importance of monitoring central venous pressure as a simple guideline for fluid therapy. Resuscitation. 1991;21(1):33-39. doi:10.1016/03009572(91)90076-B.

25. Khan ID, Sahni AK, Bharadwaj R, Lall M, Jindal AK, Sashindran VK. Emerging organisms in a tertiary healthcare set up. Med J Armed Forces India. 2014;70(2):120-128. doi:10.1016/j.mjafi.2013.09.005.

26. Khan ID, Sahni AK. Bacterial infections and emerging resistance in renal transplant recipients. Bangladesh J Med Sci. 2015;14(1):14-21. doi:10.3329/bjms.v14i1.16306.

27. Khan ID, Gupta N, Rangan NM, et al. Evaluation Of Pre and Post Analytical Variables in Clinical Microbiology Services in Multidisciplinary ICU of a Medical College And Tertiary Care Hospital. J Basic Clin Med. 2016,5(1):2-4.

28. Khan ID, Basu A, Kiran S, Trivedi S, Pandit P, Chattoraj A. DeviceAssociated Healthcare-Associated Infections (DA-HAI) and the caveat of multiresistance in a multidisciplinary intensive care unit. Med J Armed Forces India. 2017;73(3):222-231. doi:10.1016/j. mjafi.2016.10.008.

29. Khan ID. On-site Management of Frostbite in the Himalayas. Int J Travel Med Glob Health. 2017;5(1):28-32. doi:10.15171/ ijtmgh.2017.05.

30. Khan ID, Asima B, Khan SA. Operations throughput as a determinant of golden-hour in mass-gathering medicine. Int J Med and Med Res. 2017;3(1):52-58. doi:10.11603/ijmmr.2413-6077.2017.1.7804.

31. Sankoff J. Heat illnesses: a hot topic in the setting of global climate change. Aust Fam Physician. 2015;44(1-2):22-26.

32. Mandourah Y, Ocheltree A, Al Radi A, Fowler R. The epidemiology of Hajj-related critical illness: lessons for deployment of temporary critical care services*. Crit Care Med. 2012;40(3):829-834. doi:10.1097/CCM.0b013e318236f49b.

33. Bowron CS, Salahudin MM. Select Destinations The Middle East and North Africa. Saudi Arabia: Hajj Pilgrimage. In: CDC Health Information for International Travel: The Yellow Book 2016. http:// wwwnc.cdc.gov/travel/yellowbook/2016/select-destinations/saudiarabia-hajj-pilgrimage.

34. Ahmed QA, Arabi YM, Memish ZA. Health risks at the Hajj. Lancet. 2006;367(9515):1008-1015. doi:10.1016/s0140-6736(06)68429-8.

35. Mimish L. Electrocardiographic findings in heat stroke and exhaustion: a study on Makkah pilgrims. J Saudi Heart Assoc. 2012;24(1):35-39. doi:10.1016/j.jsha.2011.08.003.

36. Cleary M. Predisposing risk factors on susceptibility to exertional heat illness: clinical decision-making considerations. J Sport Rehabil. 2007;16(3):204-214. doi:10.1123/jsr.16.3.204.

37. Turkestani A, Balahmar M, Ibrahem A, Moqbel E, Memish ZA. Using health educators to improve knowledge of healthy behaviour among Hajj 1432 (2011) pilgrims. East Mediterr Health J. 2013;19 Suppl 2:S9-S12.

38. Inman WJ. Medical drones could be the next wave of emergency response. Fox News. December 14 2016. http://www.foxnews. com/health/2016/12/14/medical-drones-could-be-next-waveemergency-response.amp.html. 